\title{
PRÉ-HIDRATAÇÃO DE SEMENTES DE ERVILHA E SUA INTERFERÊNCIA NA AVALIAÇÃO DO POTENCIAL FISIOLÓGICO ${ }^{1}$
}

\author{
CAROLINE JÁCOME COSTA², FRANCISCO AMARAL VILLELA ${ }^{3}$, MIRELA ROSSETTO BERTONCELLO ${ }^{4}$, \\ MARIA ÂNGELA ANDRÉ TILLMANN ${ }^{5}$, NILSON LEMOS DE MENEZES ${ }^{6}$
}

\begin{abstract}
RESUMO-O presente trabalho teve o objetivo de estudar alterações bioquímicas e fisiológicas decorrentes da pré-hidratação de sementes de ervilha, com ênfase à lixiviação de eletrólitos. Foram utilizados lotes de sementes de ervilha, cultivares Axé e Maria, caracterizados quanto ao teor de água, geminação, primeira contagem de germinação, envelhecimento acelerado, condutividade elétrica e emergência de plântulas em campo. As sementes de cada lote foram pré-hidratadas empregando atmosfera saturada e substrato umedecido, até atingirem teores de água de 10, 12 e 14\%. Após a pré-hidratação, as sementes foram avaliadas pelos testes de condutividade elétrica e lixiviação de cálcio, potássio e magnésio. A pré-hidratação de sementes de ervilha empregando atmosfera saturada ou substrato umedecido afeta diferentemente o processo de reestruturação do sistema de membranas celulares das sementes, refletindose em alterações no padrão de lixiviação de eletrólitos. Discrepâncias são observadas entre resultados obtidos pelo teste de condutividade elétrica para avaliação do potencial fisiológico de sementes de ervilha, dependendo do procedimento adotado para a pré-hidratação das sementes.
\end{abstract}

Termos para indexação: Pisum sativum, condutividade elétrica, lixiviação de eletrólitos.

\section{PEA SEED PRE-HYDRATION AND ITS INTERFERENCE WITH THE EVALUATION OF THE PHYSIOLOGICAL POTENTIAL}

\begin{abstract}
The objective of the present research was to study biochemical and physiological changes caused by pea seed pre-hydration with emphasis on electrolyte leakage. Seed lots of the cvs. Axé and Maria were characterized for their water content, germination, first germination counting, accelerated aging, electrical conductivity and seedling emergence in the field. The seeds of each lot were pre-hydrated using two methods: saturated atmosphere and humidified substratum, until they reached 10, 12 and 14\% water content. Afterwards, the seeds were evaluated regarding calcium, potassium and magnesium leakage and electrical conductivity. The two pre-hydration methods caused changes in the electrolyte leakage pattern. Hence, both affect in different ways the seed cellular membrane restructuring system. Also, discrepancies occurred among the results from the electrical conductivity test, in which the physiological potential of the seeds was evaluated, depending on which pre-hydration process was adopted.
\end{abstract}

Index terms: Pisum sativum, electrical conductivity, electrolyte leakage.

${ }^{1}$ Submetido em 10/10/2007. Aceito para publicação em 07/02/2008. Parte da tese de Doutorado do primeiro autor, apresentada ao Programa de PósGraduação em Ciência e Tecnologia de Sementes, Faculdade de Agronomia Eliseu Maciel/Universidade Federal de Pelotas (FAEM/UFPel).

${ }^{2}$ Eng. Agra ${ }^{\text {. }}$, Pesquisadora da Embrapa Cerrados. BR 020, Km 18, Rodovia Brasília-Fortaleza, CEP 73310-970 Planaltina, DF. E-mail: caroline.costa@cpac.embrapa.br

${ }^{3}$ Eng. Agrícola, Dr., Professor Adjunto do Departamento de Fitotecnia da FAEM/UFPel. CP 354, CEP 96010-900 Pelotas, RS. E-mail: francisco.villela@ufpel.edu.br
${ }^{4}$ Estudante de Agronomia da FAEM/UFPel. E-mail: mirossetto@yahoo.com.br

${ }^{5}$ Eng. Agr ${ }^{\mathrm{a}}$, Dr $^{\mathrm{a}}$., Professora Adjunto do Departamento de Fitotecnia da FAEM/UFPel. Caixa Postal 354, CEP 96010-900 Pelotas, RS. E-mail: matilman@ufpel.edu.br

${ }^{6}$ Eng. Agro ., Dr., Professor Adjunto do Departamento de Fitotecnia da Universidade Federal de Santa Maria. Centro de Ciências Rurais, Departamento de Fitotecnia - Campus universitário - Camobi, CEP 97105 900 Santa Maria, RS. E-mail: nlmenezes@smail.ufsm.br 


\section{INTRODUÇÃO}

A manutenção da funcionalidade celular nos organismos eucariotos é altamente dependente de um sistema eficiente de compartimentalização celular. O complexo sistema de endomembranas celulares atende, em parte, a esse propósito. Dessa forma, para que as células mantenham sua funcionalidade metabólica, é imprescindível que as membranas apresentem-se estrutural e fisiologicamente íntegras.

Nos processos que envolvem a perda de água pelas células, como a dessecação ao longo da maturação das sementes, as membranas alteram seu estado físico, passando do estado cristalino líquido, mais fluido, para o estado de gel, menos fluido. Essa transição acarreta redução na distância entre os grupos-cabeça dos fosfolipídios, aumentando as interações hidrofóbicas (interações de Van der Waals) entre as cadeias dos ácidos graxos (Crowe et al., 1992).

Ao serem reidratadas, no processo natural de embebição que antecede a retomada do crescimento e desenvolvimento do embrião durante a germinação, ocorre nova transição entre os estados de gel para cristalino líquido nas membranas celulares das sementes. Se a embebição ocorrer muito rapidamente, não haverá tempo hábil para que as células retornem ao estado cristalino líquido, situação na qual ocorrem danos celulares e lixiviação de eletrólitos e outras substâncias intracelulares, caracterizando o dano por embebição (Bewley, 1997; De Castro e Hilhorst, 2004; Marcos Filho, 2005).

Trabalhos realizados com sementes de milho submetidas a tratamentos de pré-hidratação previamente à imersão em água mostram acentuada redução na lixiviação de solutos, avaliada pelo teste de condutividade elétrica (Rosa et al., 2000). Os danos por embebição são reduzidos quando a hidratação inicial das sementes ocorre com a fase de vapor de água, sob alta umidade relativa, ou quando a taxa inicial do influxo de água é reduzida através do revestimento das sementes (De Castro e Hilhorst, 2004).

Dessa forma, é possível que mecanismos moleculares de proteção ao sistema de membranas possam ser ativados durante tais tratamentos de pré-hidratação das sementes, limitando a lixiviação do conteúdo celular, garantindo a compartimentalização celular necessária e permitindo melhor desempenho das sementes durante a germinação.

Contudo, possivelmente, sementes de potencial fisiológico inferior apresentam deficiências no processo de reparo e/ou proteção ao sistema de membranas durante a fase inicial de embebição, o que poderia levar a perturbações em todas as fases subseqüentes do processo de germinação.
A disponibilidade de testes de vigor suficientemente sensíveis para detectar essas alterações metabólicas em suas fases iniciais é restrita. Dos testes disponíveis, poder-se-ia destacar o teste de condutividade elétrica, cujo princípio está diretamente relacionado à integridade das membranas celulares, avaliando indiretamente o seu grau de estruturação. Atualmente, esforços com o objetivo de padronização do teste de condutividade elétrica para avaliação do vigor de sementes de ervilha têm sido empreendidos pela pesquisa na área de ciência e tecnologia de sementes, notadamente no âmbito dos comitês internacionais da "International Seed Testing Association" - ISTA.

Entretanto, a recomendação de métodos adequados que permitam a hidratação das sementes, caso estas encontrem-se fora da faixa considerada adequada para a condução do teste (teor de água de 10\% a 14\%) necessita de aprimoramento. A ISTA recomenda dois métodos para hidratação das sementes: hidratação em substrato umedecido e hidratação em atmosfera saturada. Todavia, estudos preliminares mostram haver diferenças não apenas na velocidade de absorção de água pelas sementes entre os dois métodos, como também diferenças no ranqueamento de lotes ao utilizar os dois procedimentos.

Dessa forma, o presente trabalho teve o objetivo de estudar alterações bioquímicas e fisiológicas decorrentes da hidratação de sementes de ervilha, com ênfase à lixiviação de eletrólitos, procurando contribuir para o aperfeiçoamento dos métodos de hidratação de sementes a serem submetidas a testes para avaliação do seu potencial fisiológico.

\section{MATERIAL E MÉTODOS}

Os experimentos foram conduzidos na Faculdade de Agronomia "Eliseu Maciel", da Universidade Federal de Pelotas, nos laboratórios de Análise de Sementes e de Solos, no período de agosto de 2005 a agosto de 2006.

Foram utilizados cinco lotes de sementes de ervilha, cultivar Axé, de tegumento rugoso e quatro lotes da cultivar Maria, de tegumento liso, cedidos pela Embrapa Hortaliças. Os lotes foram caracterizados quanto ao teor de água, germinação, primeira contagem de germinação, envelhecimento acelerado, condutividade elétrica e emergência das plântulas em campo.

A germinação e o teor de água dos lotes foram determinados conforme as Regras para Análise de Sementes (Brasil, 1992), sendo a germinação conduzida em rolos de papel, empregando quatro amostras de 50 sementes, temperatura de $20^{\circ} \mathrm{C}$ e avaliações aos cinco e sete dias. $\mathrm{O}$ teor de água foi determinado em duas subamostras, empregando o método da estufa a $105 \pm 3^{\circ} \mathrm{C}$, por 24 horas. 
A primeira contagem de germinação, conduzida conjuntamente com o teste de germinação, consistiu na avaliação da percentagem de plântulas normais obtidas no quinto dia após a instalação do teste.

$\mathrm{Na}$ condução do teste de envelhecimento acelerado, seguiram-se as recomendações de Marcos Filho (1999), sendo as sementes distribuídas sobre telas de alumínio, fixadas no interior de caixas plásticas (tipo gerbox) contendo $40 \mathrm{~mL}$ de água destilada. As caixas foram fechadas e mantidas em câmara regulada a $41^{\circ} \mathrm{C}$ por 72 horas. Após esse período, as sementes foram colocadas para germinar conforme metodologia descrita anteriormente, computandose a percentagem de plântulas normais no quinto dia após a instalação do teste.

No teste de condutividade elétrica, quatro subamostras de 50 sementes de cada lote foram pesadas, colocadas em copos plásticos de volume $500 \mathrm{~mL}$, imersas em $250 \mathrm{~mL}$ de água deionizada e mantidas a $20^{\circ} \mathrm{C}$ durante 24 horas, conforme recomendações da ISTA (2004), sem, no entanto, ajustar o teor de água das sementes para a faixa de 10-14\%. Após esse período, determinou-se a condutividade elétrica da solução. Os resultados foram expressos em $\mu \mathrm{S} . \mathrm{cm}^{-1} \cdot \mathrm{g}^{-1} \mathrm{de}$ sementes.

Para a emergência de plântulas em campo, quatro subamostras de 100 sementes de cada lote foram semeadas em sulcos de quatro metros de comprimento e 0,05 metro de profundidade, cobertas com uma fina camada de solo. A avaliação foi realizada aos 10 dias após a semeadura, computando-se o número de plântulas emergidas.

Amostras de sementes de cada lote foram submetidas a dois métodos de hidratação, até atingirem três teores de água (10, 12 e 14\%), monitorados pelo ganho de massa, resultando 30 tratamentos para a cultivar Axé (5 lotes x 2 métodos de hidratação x 3 teores de água) e 24 tratamentos para a cultivar Maria (4 lotes x 2 métodos de hidratação x 3 teores de água). Os métodos de hidratação estão relacionados a seguir.

- Hidratação em substrato umedecido - as sementes foram mantidas entre quatro folhas de papel germitest, umedecidas com quantidade de água destilada equivalente a 2,5 vezes a sua massa, formando-se rolos semelhantes àqueles confeccionados para condução do teste de germinação, a $20^{\circ} \mathrm{C}$, até atingirem os teores de água desejados.

- Hidratação em atmosfera saturada - as sementes foram colocadas sobre telas de alumínio, fixadas no interior de caixas plásticas (tipo gerbox), contendo $40 \mathrm{~mL}$ de água destilada no fundo, mantidas em câmara a $20^{\circ} \mathrm{C}$, até atingirem os teores de água desejados.
O teor de água das sementes foi monitorado através de pesagens periódicas de amostras e determinações pela fórmula Pi (100-Ui) = Pf (100-Uf), onde:

Pi e Pf correspondem aos pesos inicial e final das amostras, respectivamente;

Ui e Uf correspondem às umidades inicial e final, em base úmida, das amostras, respectivamente.

Após a hidratação das sementes, foram retiradas amostras, destinadas à condução dos testes de condutividade elétrica e lixiviação de potássio, cálcio e magnésio.

O teste de condutividade elétrica foi conduzido conforme descrito anteriormente.

Para a determinação da lixiviação de potássio, cálcio e magnésio, quatro amostras de 25 sementes foram imersas em $125 \mathrm{~mL}$ de água deionizada, a $20^{\circ} \mathrm{C}$, por seis horas. $\mathrm{O}$ teor de potássio foi determinado por espectrofotometria de chama, a partir de alíquotas de $1 \mathrm{~mL}$, retiradas da água de imersão das sementes e diluídas em $5 \mathrm{~mL}$ de água destilada. Os teores de cálcio e magnésio foram determinados diretamente na água de imersão das sementes, por espectrofotometria de absorção atômica. Os resultados foram expressos em mg de cada íon por litro de solução.

O período de seis horas de imersão das sementes foi definido com base em trabalhos anteriores, realizados com sementes de soja e ervilha, nos quais estabeleceu-se que, após cinco horas de imersão das sementes em água, completa-se o processo de absorção de água pelas sementes, estando os cotilédones e eixo embrionário, completamente hidratados (Duke e Kakefuda, 1981; Pietrzak et al., 2002).

Para a caracterização dos lotes, os dados de germinação, primeira contagem de germinação, emergência de plântulas em campo, envelhecimento acelerado, condutividade elétrica e lixiviação de cálcio, potássio e magnésio foram submetidos à análise de variância, utilizando-se o delineamento inteiramente casualizado, com quatro tratamentos (lotes) para a cultivar Maria e cinco tratamentos para a cultivar Axé. As médias foram comparadas pelo teste de Tukey, a 5\% de probabilidade.

Para cada cultivar, os dados relativos aos efeitos de lotes, métodos de hidratação e teores de água foram submetidos à análise de variância utilizando-se o delineamento inteiramente casualizado, em esquema fatorial, com quatro lotes, dois métodos de hidratação e três teores de água, para a cultivar Maria, e cinco lotes, dois métodos de hidratação e três teores de água, para a cultivar Axé. As médias para o fator teores de água foram analisadas por regressão polinomial, ao nível de $5 \%$ de probabilidade e para os fatores lotes e métodos de hidratação, foram comparadas pelo teste de Tukey, a 5\% de probabilidade, conforme o caso. 
Os dados de germinação, primeira contagem de germinação, emergência de plântulas em campo e envelhecimento acelerado foram transformados em arcsen $(\% / 100)^{1 / 2}$. Nas tabelas, foram apresentados os dados originais.

\section{RESULTADOS E DISCUSSÃO}

\section{Caracterização dos lotes}

$\mathrm{Na}$ Tabela 1, são apresentados os resultados de teor de água, germinação, primeira contagem de germinação, emergência de plântulas em campo, envelhecimento acelerado e condutividade elétrica, utilizados na caracterização do potencial fisiológico dos lotes de sementes de ervilha. Conforme observado, embora os lotes apresentem diferenças quanto ao potencial fisiológico, seus teores de água foram similares, variando de $8,2 \%$ a $8,7 \%$, na cultivar Axé, e de $8,4 \%$ a $8,7 \%$ na cultivar Maria. Da mesma forma, a germinação dos lotes também foi semelhante, variando de $94 \%$ a $96 \%$, na cultivar Maria e de $87 \%$ a $96 \%$, na cultivar Axé, sendo similares os lotes A, B, C e D e o lote E, inferior ao lote D.

Verificou-se que, dos testes empregados para avaliação do potencial fisiológico dos lotes de sementes de ervilha, cultivar Axé, os de envelhecimento acelerado e emergência de plântulas em campo possibilitaram classificar os lotes em níveis de vigor, separando-os em lotes de alto (lote D), médio (lotes B, C e E) e baixo (lote A) potencial fisiológico. Para a cultivar Maria, os resultados do teste de emergência de plântulas evidenciaram a superioridade do loteF relativamente aos lotes $\mathrm{G}$ e $\mathrm{H}$, sendo o lote I considerado como de potencial fisiológico intermediário. O teste de condutividade elétrica, por outro lado, possibilitou apenas a separação do lote $\mathrm{H}$, considerado de menor potencial fisiológico, relativamente aos demais.

2. Classificação dos lotes, em níveis de vigor, baseada no teste de condutividade elétrica, após diferentes métodos de pré-hidratação das sementes

As regras internacionais para análise de sementes estabelecem que, para a condução do teste de condutividade elétrica em ervilha, o teor de água das sementes deve encontrar-se entre $10 \%$ e $14 \%$ (ISTA, 2004). Todavia, sabese que, para algumas regiões produtoras de sementes de ervilha no Brasil, notadamente o Centro-Oeste, é possível encontrar lotes de sementes prontos para a comercialização com teores de água inferiores a 10\%, dadas as condições climáticas predominantes na região. Nesses casos, a adoção do teste de condutividade elétrica para avaliação do potencial fisiológico dos lotes ficaria condicionada à pré-hidratação das sementes.

Considerando os resultados apresentados nas Tabelas 2 e 3, em que se avaliou o comportamento de lotes de sementes de ervilha submetidos a diferentes métodos de hidratação previamente à condução do teste de condutividade elétrica, observou-se que, para a cultivar Axé, de tegumento rugoso,

TABELA 1. Médias do teor de água (TA), germinação (G), primeira contagem de germinação (PC), emergência de plântulas em campo (EC), envelhecimento acelerado (EA) e condutividade elétrica (CE) de diferentes lotes de sementes de ervilha de duas cultivares. Pelotas/RS, 2006.

\begin{tabular}{cccccccc}
\hline \multirow{2}{*}{ CUltivaR } & LOTES & $\begin{array}{c}\text { TA } \\
(\%)\end{array}$ & $\begin{array}{c}\mathrm{G} \\
(\%)\end{array}$ & $\begin{array}{c}\text { PC } \\
(\%)\end{array}$ & $\begin{array}{c}\text { EC } \\
(\%)\end{array}$ & $\begin{array}{c}\text { EA } \\
(\%)\end{array}$ & $\begin{array}{c}\text { CE } \\
\left(\mu \mathrm{S} \cdot \mathrm{cm}^{-1} \cdot \mathrm{g}^{-1}\right)\end{array}$ \\
\hline \multirow{6}{*}{ Axé } & $\mathrm{A}$ & 8,3 & $95 \mathrm{ab}$ & $88 \mathrm{a}$ & $54 \mathrm{~d}$ & $64 \mathrm{c}$ & $28,51 \mathrm{c}$ \\
& $\mathrm{B}$ & 8,5 & $94 \mathrm{ab}$ & $86 \mathrm{a}$ & $74 \mathrm{~b}$ & $83 \mathrm{~b}$ & $16,12 \mathrm{a}$ \\
& $\mathrm{C}$ & 8,7 & $89 \mathrm{ab}$ & $80 \mathrm{a}$ & $66 \mathrm{c}$ & $74 \mathrm{bc}$ & $20,78 \mathrm{~b}$ \\
& $\mathrm{D}$ & 8,4 & $96 \mathrm{a}$ & $86 \mathrm{a}$ & $86 \mathrm{a}$ & $94 \mathrm{a}$ & $15,64 \mathrm{a}$ \\
& $\mathrm{E}$ & 8,2 & $87 \mathrm{~b}$ & $84 \mathrm{a}$ & $67 \mathrm{c}$ & $76 \mathrm{bc}$ & $19,24 \mathrm{ab}$ \\
\hline \multirow{6}{*}{ Maria } & $\mathrm{CV}(\%)$ & & 5,31 & 5,44 & 7,38 & 7,48 & 8,39 \\
& $\mathrm{~F}$ & 8,6 & $94 \mathrm{a}$ & $93 \mathrm{a}$ & $83 \mathrm{a}$ & $91 \mathrm{a}$ & $16,50 \mathrm{a}$ \\
& $\mathrm{G}$ & 8,7 & $94 \mathrm{a}$ & $90 \mathrm{a}$ & $77 \mathrm{~b}$ & $86 \mathrm{a}$ & $16,28 \mathrm{a}$ \\
& $\mathrm{H}$ & 8,4 & $94 \mathrm{a}$ & $90 \mathrm{a}$ & $78 \mathrm{~b}$ & $88 \mathrm{a}$ & $18,84 \mathrm{~b}$ \\
& $\mathrm{I}$ & 8,4 & $96 \mathrm{a}$ & $94 \mathrm{a}$ & $80 \mathrm{ab}$ & $91 \mathrm{a}$ & $14,72 \mathrm{a}$ \\
\hline
\end{tabular}

Médias seguidas pela mesma letra na coluna, para cada cultivar, não diferem entre si pelo teste de Tukey a $5 \%$ de probabilidade. 
TABELA 2. Médias da condutividade elétrica da água de imersão de cinco lotes de sementes de ervilha, cultivar Axé, previamente submetidas à hidratação em atmosfera saturada e substrato umedecido até atingirem teores de água de 10, 12 e 14\%. Pelotas/RS, 2006.

\begin{tabular}{|c|c|c|c|c|c|c|}
\hline \multirow[b]{2}{*}{ Lotes } & \multicolumn{3}{|c|}{ Atmosfera Saturada } & \multicolumn{3}{|c|}{ Substrato Umedecido } \\
\hline & $10 \%$ & $12 \%$ & $14 \%$ & $10 \%$ & $12 \%$ & $14 \%$ \\
\hline \multicolumn{7}{|c|}{ - } \\
\hline A & $26,76 \mathrm{c}$ & $29,42 \mathrm{c}$ & $26,12 \mathrm{c}$ & $29,14 \mathrm{c}$ & $26,78 \mathrm{c}$ & $24,08 \mathrm{c}$ \\
\hline B & $24,03 \mathrm{bc}$ & $21,37 \mathrm{~b}$ & $20,78 \mathrm{~b}$ & $19,70 \mathrm{ab}$ & $21,09 \mathrm{~b}$ & $18,16 \mathrm{~b}$ \\
\hline $\mathrm{C}$ & $21,18 \mathrm{~b}$ & $20,17 \mathrm{~b}$ & $18,60 \mathrm{ab}$ & $21,15 b$ & $19,77 \mathrm{ab}$ & $18,66 \mathrm{~b}$ \\
\hline D & $17,80 \mathrm{a}$ & $16,62 \mathrm{a}$ & $15,64 \mathrm{a}$ & $17,10 \mathrm{a}$ & $17,28 \mathrm{a}$ & $15,00 \mathrm{a}$ \\
\hline E & $22,77 \mathrm{~b}$ & $16,44 \mathrm{a}$ & $16,77 \mathrm{a}$ & $21,28 \mathrm{~b}$ & $17,50 \mathrm{a}$ & $16,48 \mathrm{ab}$ \\
\hline
\end{tabular}

CV (\%) $\quad 7,48$

Médias seguidas pela mesma letra, na coluna, não diferem entre si pelo teste de Tukey a 5\% de probabilidade.

TABELA 3. Médias da condutividade elétrica da água de imersão de quatro lotes de sementes de ervilha, cultivar Maria, previamente submetidas à hidratação em atmosfera saturada e substrato umedecido até atingirem teores de água de 10, 12 e 14\%. Pelotas/RS, 2006.

\begin{tabular}{|c|c|c|c|}
\hline Lotes & $10 \%$ & $12 \%$ & $14 \%$ \\
\hline \multicolumn{4}{|c|}{ - } \\
\hline F & $20,00 \mathrm{~b}$ & $16,87 \mathrm{ab}$ & $15,53 \mathrm{a}$ \\
\hline G & $19,16 \mathrm{~b}$ & $16,08 \mathrm{a}$ & $15,57 \mathrm{a}$ \\
\hline $\mathrm{H}$ & $19,63 \mathrm{~b}$ & $17,38 \mathrm{~b}$ & $16,86 \mathrm{~b}$ \\
\hline $\mathrm{I}$ & $17,24 \mathrm{a}$ & $15,72 \mathrm{a}$ & $14,95 \mathrm{a}$ \\
\hline
\end{tabular}

Médias seguidas pela mesma letra, na coluna, não diferem entre si pelo teste de Tukey a 5\% de probabilidade.

houve diferença na classificação dos lotes dependendo tanto do método de pré-hidratação empregado (atmosfera saturada ou substrato umedecido), como dos teores de água dentro de cada método (Tabela 2). Para a cultivar Maria, entretanto, as diferenças na classificação dos lotes foram independentes dos métodos de pré-hidratação empregados, diferindo apenas quanto ao teor de água das sementes (Tabela 3).

$\mathrm{O}$ fato de o método empregado para hidratar as sementes ter afetado de forma distinta as duas cultivares pode ser reflexo das peculiaridades de cada uma delas quanto à sua composição química e características morfo-anatômicas relacionadas aos tecidos da própria semente, notadamente o tegumento. Desse modo, verificou-se que o método de pré-hidratação empregado não provocou diferenças na classificação dos lotes de sementes da cultivar Maria, quanto ao potencial fisiológico, sendo afetado apenas pelos teores de água alcançados pelas amostras previamente à execução do teste de condutividade elétrica. Nesse caso, verificou-se que a hidratação das sementes até teores de água de 12 a 14\%, previamente à execução do teste de condutividade elétrica, promoveu classificação dos lotes semelhante à obtida sem a hidratação das sementes (Tabelas 1 e 3).

Todavia, a hidratação das sementes até o teor de água de $10 \%$, previamente à condução do teste de condutividade elétrica, alterou completamente a classificação dos lotes, quanto ao nível de vigor, comparativamente aos resultados obtidos no teste de condutividade elétrica sem a realização da pré-hidratação das sementes. Essa classificação foi, contudo, semelhante à obtida no teste de emergência de plântulas.

No caso da cultivar Axé, a realização do teste de condutividade elétrica após o ajuste do teor de água das sementes para 10\%, empregando substrato umedecido, permitiu a obtenção de resultados semelhantes aos do teste de emergência de plântulas, separando lotes de alto (lote D), médio (lotes B, C e E) e baixo (lote A) potencial fisiológico (Tabela 2).

Nos gráficos que apresentam a tendência da condutividade elétrica da água de imersão de sementes de ervilha em função 
da pré-hidratação das sementes até diferentes teores de água, foram apresentados apenas os resultados mais significativos de cada cultivar, representativos do padrão observado nos demais lotes.

Os gráficos apresentados na Figura 1, referentes à condutividade elétrica da água de imersão de sementes de ervilha submetidas à pré-hidratação utilizando dois métodos até alcançarem diferentes teores de água, demonstraram haver decréscimo da condutividade elétrica conforme incrementouse o teor de água das sementes previamente à condução do teste. Isso pode ser explicado pelo maior grau de estruturação do sistema de membranas celulares quando as sementes atingiram maior nível de hidratação, independentemente do método empregado. A melhor estruturação das membranas celulares, por sua vez, tende a limitar a lixiviação de íons e outras substâncias presentes no interior das sementes, reduzindo a condutividade elétrica da água de imersão, conforme observações anteriores (Rossetto et al., 1997; Hoekstra et al., 1999; Rosa et al., 2000; Rodrigues et al., 2006). Além disso, verificou-se, entre as duas cultivares estudadas, maiores valores de condutividade elétrica para as sementes da cultivar Axé, de tegumento rugoso, em relação às da cultivar Maria, de tegumento liso (Tabelas 2 e 3 e Figura 1). Nesse sentido, vários trabalhos têm associado a lixiviação de substâncias intracelulares durante a embebição de sementes com o seu desempenho em campo (Duke et al., 1986; Shephard e Naylor, 1996; Miguel e Marcos Filho, 2002). A razão para essa associação não está totalmente elucidada, mas os progressos obtidos até o momento apontam que a maior lixiviação de exsudatos pode refletir um quadro geral de deterioração dos tecidos da semente, além de constituírem substrato favorável ao desenvolvimento de microrganismos patogênicos. Pode ser, ainda, que a presença de grande quantidade de exsudatos seja resultante de um processo de ruptura celular ocasionada pela rápida embebição de água pelas sementes, o que também criaria sítios favoráveis ao ataque de patógenos (Duke et al., 1986).

Os resultados obtidos no presente trabalho sugerem a possibilidade de haver discrepâncias entre resultados obtidos pelo teste de condutividade elétrica ao utilizá-lo com a
Lote A

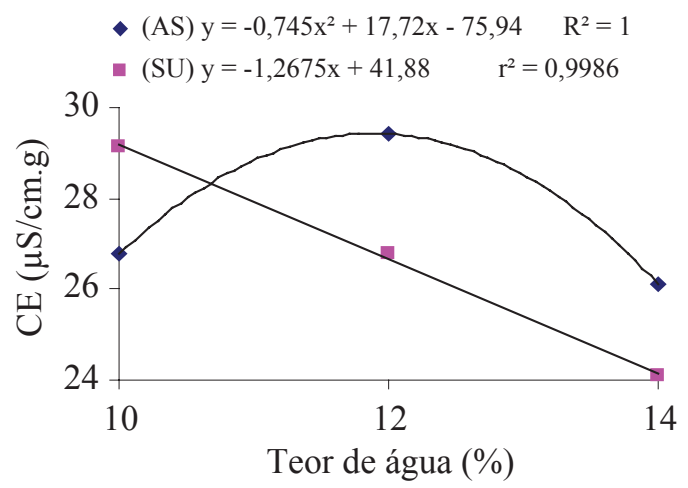

Lote $\mathrm{G}$

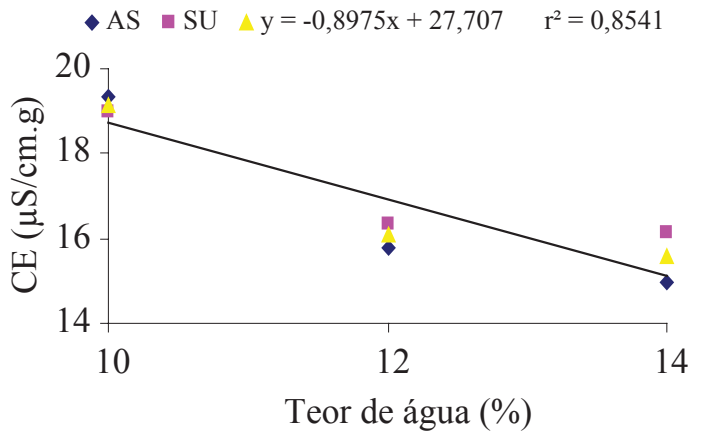

Lote B

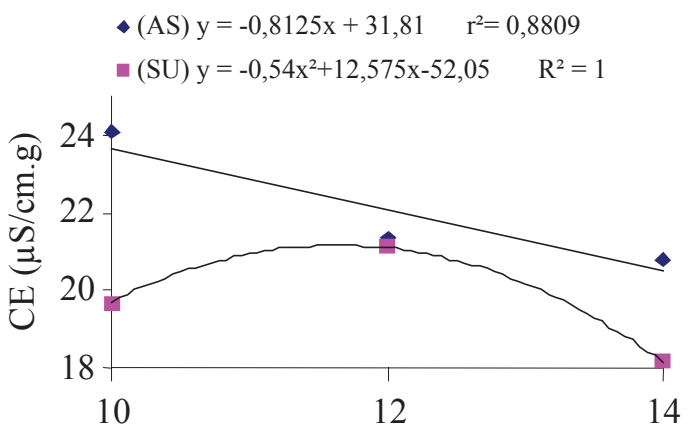

Lote I

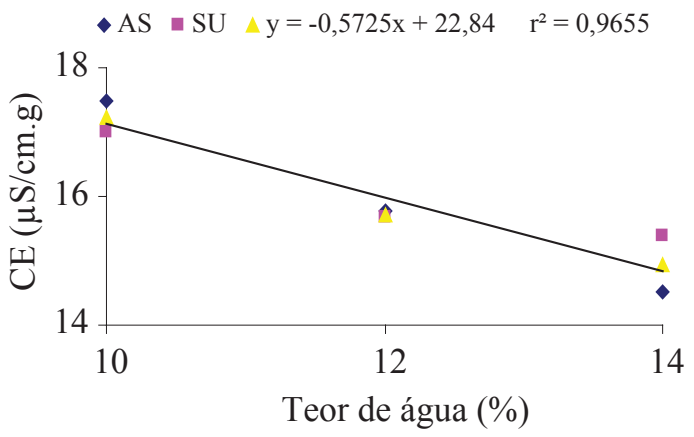

FIGURA 1. Condutividade elétrica da água de imersão de sementes de ervilha, cultivares Axé (lotes A e B) e Maria (lotes G e I), submetidas à hidratação empregando atmosfera saturada (AS) e substrato umedecido (SU) até atingirem diferentes teores de água. Pelotas/RS, 2006. 
finalidade de classificar lotes de sementes de ervilha quanto ao potencial fisiológico, dependendo do procedimento adotado para a pré-hidratação das sementes, caso seja necessário. Essa ocorrência implica a necessidade de condução de estudos adicionais que subsidiem a escolha de um método padronizado relacionado à hidratação de sementes a serem submetidas ao teste de condutividade elétrica e mesmo a outros testes nos quais o teor de água das amostras represente característica importante na obtenção dos resultados.

\section{Lixiviação de cálcio, potássio e magnésio após a pré- hidratação das sementes}

Durante as seis horas de imersão das sementes em água, a quantidade de cálcio lixiviada não pôde ser detectada por encontrar-se abaixo do limite de detecção do método empregado. É possível que, devido ao maior raio atômico, os íons de cálcio tenham apresentado maior dificuldade em transpor as membranas celulares, o que limitou a sua concentração na água após a imersão das sementes.

Considerando a lixiviação de potássio, a concentração desse íon na água de imersão das sementes, após seis horas, variou, na cultivar Axé, de 26,90 a 59,06 mg . $\mathrm{L}^{-1}$ e de 16,74 a 25,78 mg . $\mathrm{L}^{-1}$, na cultivar Maria (Tabela 4). Para a lixiviação de magnésio, esses valores variaram, na cultivar Axé, de 0,51 a $0,77 \mathrm{mg} . \mathrm{L}^{-1} \mathrm{e}$ de 0,07 a $0,35 \mathrm{mg} . \mathrm{L}^{-1}$, na cultivar Maria (Tabela 5).
A lixiviação de potássio como critério para a classificação dos lotes em níveis vigor só foi eficiente para a cultivar Axé. Nesse caso, foi possível confirmar a classificação dos lotes obtida através dos resultados do teste de emergência de plântulas, sendo necessário o ajuste do teor de água das sementes para 10 e $12 \%$, empregando atmosfera saturada (Tabela 4).

Os resultados obtidos no presente trabalho resultantes da lixiviação de potássio e magnésio (Tabelas 4 e 5) e refletidos na condutividade elétrica da solução de imersão das sementes (Tabelas 2 e 3), permitiriam predizer desempenho inferior das sementes dos lotes da cultivar Axé em relação à cultivar Maria. Isso foi confirmado ao comparar o desempenho relativo das sementes dos lotes das duas cultivares nos testes de germinação e emergência de plântulas em campo.

Em um estudo comparativo da lixiviação de metabólitos durante a embebição de sementes de diferentes genótipos de milho doce, Wann (1986) encontrou maiores valores de condutividade elétrica para os genótipos que apresentavam o pericarpo mais enrugado. $\mathrm{O}$ autor sugeriu que, quanto mais enrugado o pericarpo, maior a suscetibilidade a danos mecânicos durante as etapas de produção e beneficiamento dessas sementes.

No caso das sementes de ervilha, sabe-se que as diferenças entre os genótipos que apresentam o tegumento

TABELA 4. Teor de potássio $\left(K^{+}\right)$da água de imersão de sementes de ervilha, lotes de duas cultivares, previamente submetidas à hidratação em atmosfera saturada e substrato umedecido até atingirem teores de água de 10, 12 e 14\%. Pelotas/RS, 2006.

\begin{tabular}{|c|c|c|c|c|c|c|c|}
\hline \multirow[b]{2}{*}{ Cultivar } & \multirow[b]{2}{*}{ Lotes } & \multicolumn{3}{|c|}{ Atmosfera Saturada } & \multicolumn{3}{|c|}{ Substrato Umedecido } \\
\hline & & $10 \%$ & $12 \%$ & $14 \%$ & $10 \%$ & $12 \%$ & $14 \%$ \\
\hline \multicolumn{8}{|c|}{ 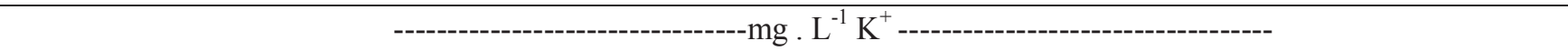 } \\
\hline \multirow{5}{*}{ Axé } & A & $45,75 \mathrm{~d}$ & $48,46 \mathrm{~d}$ & $50,39 \mathrm{c}$ & $59,06 \mathrm{c}$ & $50,00 \mathrm{~d}$ & $48,65 \mathrm{c}$ \\
\hline & B & $41,70 \mathrm{c}$ & $37,26 \mathrm{c}$ & 36,68 a & $37,07 \mathrm{~b}$ & $36,10 \mathrm{c}$ & $37,84 \mathrm{~b}$ \\
\hline & $\mathrm{C}$ & $31,50 \mathrm{ab}$ & $31,70 \mathrm{~b}$ & $41,75 \mathrm{~b}$ & $29,42 \mathrm{a}$ & $31,50 \mathrm{~b}$ & $37,88 \mathrm{~b}$ \\
\hline & $\mathrm{D}$ & $29,57 \mathrm{a}$ & $27,66 \mathrm{a}$ & $37,47 \mathrm{a}$ & $30,21 \mathrm{a}$ & $30,16 a b$ & $36,29 \mathrm{~b}$ \\
\hline & E & $33,48 \mathrm{~b}$ & $28,16 \mathrm{ab}$ & $34,64 \mathrm{a}$ & $29,03 \mathrm{a}$ & $26,90 \mathrm{a}$ & $31,16 \mathrm{a}$ \\
\hline CV (\%) & & & & 5,19 & & & \\
\hline \multirow{4}{*}{ Maria } & $\mathrm{F}$ & $22,87 \mathrm{~b}$ & $18,47 \mathrm{a}$ & $21,55 \mathrm{~b}$ & $20,96 \mathrm{~b}$ & $21,84 \mathrm{~b}$ & $20,52 \mathrm{a}$ \\
\hline & G & $24,24 \mathrm{~b}$ & $22,21 \mathrm{~b}$ & $25,78 \mathrm{c}$ & $22,61 \mathrm{~b}$ & $22,31 \mathrm{~b}$ & $25,58 \mathrm{~b}$ \\
\hline & $\mathrm{H}$ & $17,81 \mathrm{a}$ & $16,74 \mathrm{a}$ & $19,71 \mathrm{ab}$ & $18,25 \mathrm{a}$ & $18,10 \mathrm{a}$ & $20,04 \mathrm{a}$ \\
\hline & I & $18,39 \mathrm{a}$ & $17,66 \mathrm{a}$ & $17,51 \mathrm{a}$ & $18,39 \mathrm{a}$ & $17,66 \mathrm{a}$ & $19,70 \mathrm{a}$ \\
\hline
\end{tabular}

Médias seguidas pela mesma letra na coluna, para cada cultivar, não diferem entre si pelo teste de Tukey a 5\% de probabilidade. 
TABELA 5. Teor de magnésio $\left(\mathrm{Mg}^{++}\right)$da água de imersão de sementes de ervilha, lotes de duas cultivares, previamente submetidas à hidratação em atmosfera saturada e substrato umedecido até atingirem teores de água de 10, 12 e 14\%. Pelotas/RS, 2006.

\begin{tabular}{|c|c|c|c|c|c|c|c|}
\hline \multirow[b]{2}{*}{ Cultivar } & \multirow[b]{2}{*}{ Lotes } & \multicolumn{3}{|c|}{ Atmosfera Saturada } & \multicolumn{3}{|c|}{ Substrato Umedecido } \\
\hline & & $10 \%$ & $12 \%$ & $14 \%$ & $10 \%$ & $12 \%$ & $14 \%$ \\
\hline \multicolumn{8}{|c|}{ 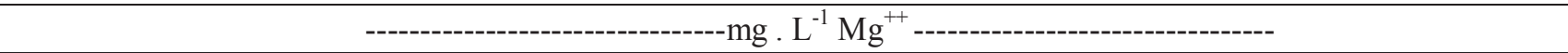 } \\
\hline \multirow{5}{*}{ Axé } & $\mathrm{A}$ & $0,60 \mathrm{ab}$ & $0,56 \mathrm{a}$ & $0,66 \mathrm{bc}$ & $0,70 \mathrm{a}$ & $0,53 \mathrm{ab}$ & $0,56 \mathrm{a}$ \\
\hline & B & $0,75 \mathrm{c}$ & $0,58 \mathrm{a}$ & $0,51 \mathrm{a}$ & $0,66 \mathrm{a}$ & $0,52 \mathrm{a}$ & $0,59 \mathrm{a}$ \\
\hline & $\mathrm{C}$ & $0,66 \mathrm{abc}$ & $0,57 \mathrm{a}$ & $0,59 \mathrm{ab}$ & $0,62 \mathrm{a}$ & $0,60 \mathrm{ab}$ & $0,62 \mathrm{a}$ \\
\hline & $\mathrm{D}$ & $0,71 \mathrm{bc}$ & $0,56 \mathrm{a}$ & $0,67 \mathrm{bc}$ & $0,70 \mathrm{a}$ & $0,62 \mathrm{ab}$ & $0,51 \mathrm{a}$ \\
\hline & $\mathrm{E}$ & $0,55 \mathrm{a}$ & $0,65 \mathrm{a}$ & $0,73 \mathrm{c}$ & $0,68 \mathrm{a}$ & $0,64 \mathrm{~b}$ & $0,77 \mathrm{~b}$ \\
\hline CV $(\%)$ & \multicolumn{7}{|c|}{9,41} \\
\hline \multirow{4}{*}{ Maria } & $\mathrm{F}$ & $0,35 \mathrm{c}$ & $0,17 \mathrm{~b}$ & $0,16 b$ & $0,19 \mathrm{c}$ & $0,22 \mathrm{~b}$ & $0,15 \mathrm{~b}$ \\
\hline & G & $0,27 \mathrm{~b}$ & $0,20 \mathrm{~b}$ & $0,27 \mathrm{c}$ & $0,19 \mathrm{c}$ & $0,20 \mathrm{~b}$ & $0,24 \mathrm{c}$ \\
\hline & $\mathrm{H}$ & $0,11 \mathrm{a}$ & $0,12 \mathrm{a}$ & $0,08 \mathrm{a}$ & $0,08 \mathrm{a}$ & $0,08 \mathrm{a}$ & $0,14 \mathrm{~b}$ \\
\hline & I & $0,10 \mathrm{a}$ & $0,07 \mathrm{a}$ & $0,08 \mathrm{a}$ & $0,13 \mathrm{~b}$ & $0,09 \mathrm{a}$ & $0,07 \mathrm{a}$ \\
\hline
\end{tabular}

Médias seguidas pela mesma letra na coluna, para cada cultivar, não diferem entre si pelo teste de Tukey a 5\% de probabilidade.

rugoso e os que apresentam o tegumento liso são decorrentes de alterações gênicas que afetam tanto a taxa de síntese quanto a qualidade e estrutura do amido produzido durante o desenvolvimento embrionário. Assim, nas sementes de ervilha de tegumento rugoso, os grânulos de amido apresentamse menores e profundamente fissurados, relativamente às sementes de tegumento liso, além do amido apresentar maior conteúdo de amilose em relação à amilopectina (Denyer et al., 1997). A mutação no gene que confere o caráter rugoso ou liso das sementes de ervilha resulta na redução da atividade de enzimas envolvidas na ramificação do amido, levando à redução na taxa de síntese do próprio amido e, conseqüentemente, ao acúmulo de metabólitos situados no início da rota metabólica, como a sacarose. O aumento na concentração de sacarose, por sua vez, resulta em maior potencial osmótico, o que conduz à maior absorção de água ao longo do desenvolvimento das sementes. Como resultado, observa-se maior relação entre a massa fresca e a massa seca das sementes e maior volume e tamanho médio das células. Isso leva à maior deformação dos tecidos que compõem o tegumento, notadamente a testa, após a perda de água no processo de maturação das sementes (Smith e Denyer, 1992). Além disso, o aumento no conteúdo de sacarose interfere em outras rotas metabólicas, como aquelas relacionadas à síntese de proteínas de reserva e de lipídios.
Dessa forma, nos genótipos de tegumento rugoso, pode ser que maiores teores de açúcares solúveis presentes nas sementes por ocasião da dessecação ao final do processo de maturação provoquem maior rapidez na saída de água das sementes e menor aderência do tegumento aos cotilédones, aumentando não somente a suscetibilidade das sementes aos danos mecânicos durante a produção e beneficiamento, mas conferindo-lhes, por si só, menor potencial fisiológico inicial. A maior suscetibilidade das sementes da cultivar Axé a danos mecânicos pode resultar em maior incidência de rompimentos e fissuras no tegumento o que, segundo Duke et al. (1986), em sementes de soja, acarreta maior suscetibilidade à ocorrência de danos por embebição e menor sobrevivência das plântulas.

Nesse sentido, pode-se afirmar que as sementes da cultivar Axé, cujo desempenho fisiológico mostrou-se inferior ao das sementes da cultivar Maria, apresentaramse mais sensíveis em relação aos métodos empregados para promover sua hidratação previamente à condução do teste de condutividade elétrica, sendo afetadas de forma diferenciada conforme o método adotado.

Como a principal diferença entre os dois métodos utilizados, quanto aos efeitos, evidencia-se na velocidade de entrada de água nas sementes, observa-se que esta é uma característica importante a ser considerada no estabelecimento do método mais adequado para promover a pré-hidratação das 
sementes, uma vez que aquelas que apresentem diferenças no potencial fisiológico tendem a se comportar de maneira distinta ao sofrerem diferentes taxas de absorção de água.

Essa premissa já foi anteriormente considerada por Rodrigues et al. (2006), ao investigarem a influência de tratamentos de pré-hidratação em sementes de soja na eficiência do teste de condutividade elétrica. Do mesmo modo, de acordo com Marcos Filho (2005), sementes mais vigorosas conseguem reestruturar mais rápida $\mathrm{e}$ eficientemente seu sistema de membranas na fase inicial do processo de hidratação comparativamente às sementes com maior grau de deterioração.

A rápida entrada de água em sementes que apresentam baixo teor de água pode desencadear alterações na conformação e estrutura do sistema de membranas celulares que podem ser transitórias ou permanentes, dependendo da intensidade dos danos (Hoekstra et al., 1999).

Para Marcos Filho (2005), diferenças muito acentuadas entre os potenciais hídricos das sementes e do substrato podem acarretar problemas sérios, devido à entrada muito rápida de água nas sementes, especialmente nas menos vigorosas, ocasionando os danos por embebição, ou seja, a liberação de grandes quantidades de exsudatos e ruptura da estrutura celular. Segundo o autor, as sementes com teores de água inferiores a $11 \%$ seriam mais sensíveis a esses danos.

Nesse sentido, é possível que, em genótipos naturalmente mais suscetíveis ao dano por embebição, seja preferível que a hidratação das sementes previamente à condução do teste de condutividade elétrica ocorra mais lentamente, de modo que o sistema de membranas tenha tempo hábil para a reparação de possíveis danos pré-existentes e o restabelecimento de sua integridade e funcionalidade, capacitando a semente para a retomada do crescimento após ganhos adicionais de água ao longo do processo germinativo.

Daí serem alterações sutis, desencadeadas no início do processo de embebição das sementes, as mais sensíveis do ponto de vista da identificação de diferenças entre lotes que apresentam pequenas diferenças no potencial fisiológico. Tais alterações, por sua vez, só conseguem ser detectadas através de testes sensíveis às modificações que ocorrem ao longo do processo de reestruturação celular característico das primeiras horas de embebição das sementes e relacionadas a esse processo. Desse modo, alterações que envolvam modificações na permeabilidade das membranas celulares, decorrentes da reestruturação de sua integridade e indiretamente detectadas pelo teste de condutividade elétrica podem, sendo o teste adequadamente conduzido, levar a resultados que auxiliem na distinção qualitativa entre lotes de sementes.
No que se refere aos procedimentos a serem adotados para promover a pré-hidratação de lotes de sementes que se encontrem fora da faixa considerada adequada para a execução de testes específicos, como o teste de condutividade elétrica, recomenda-se a realização de novas investigações que permitam relacionar métodos mais adequados para esse propósito. Os resultados obtidos nesse trabalho constituem um ponto de partida, todavia, novos caminhos devem ser percorridos e outros aspectos deverão ser avaliados.

\section{CONCLUSÕES}

A pré-hidratação de sementes de ervilha empregando atmosfera saturada ou substrato umedecido afeta diferentemente o processo de reestruturação do sistema de membranas celulares, refletindo-se em alterações no padrão de lixiviação de eletrólitos.

Discrepâncias são observadas entre resultados obtidos pelo teste de condutividade elétrica para avaliação do potencial fisiológico de sementes de ervilha, dependendo do procedimento adotado para a pré-hidratação das sementes.

\section{AGRADECIMENTOS}

Ao CNPq, pelo apoio financeiro; ao Dr. Warley Marcos Nascimento, pesquisador da Embrapa Hortaliças, pelo fornecimento das sementes utilizadas nos experimentos; ao amigo Alexei de Campos Dianese, pesquisador da Embrapa Cerrados, pelo auxílio na elaboração do resumo em inglês.

\section{REFERÊNCIAS}

BEWLEY, J. D. Seed germination and dormancy. The Plant Cell, Rockville, v.9, p.1055-1066, 1997.

BRASIL. Ministério da Agricultura e da Reforma Agrária. Regras para análise de sementes. Brasília: SNDA/DNDV/ CLAV, 1992. 365p.

CROWE, J.H.; HOEKSTRA, F.A.; CROWE, L.M. Anhydrobiosis. Annual Review of Physiology, Palo Alto, v.54, p.570-599, 1992.

DE CASTRO, R. D.; HILHORST, H. W. M. Embebição e reativação do metabolismo. In: FERREIRA, A. G.; BORGHETTI, F. (Ed.). Germinação: do básico ao aplicado. Porto Alegre: Artmed, 2004. p.149-162.

DENYER, K.; BARBER, L.M.; EDWARDS, E.A.; SMITH, A.M.; WANG, T.L. Two isoforms of the GBSSI class of granule-bound starch synthase are differentially expressed in 
the pea plant. Plant, Cell and Environment, Oxford, v.20, p.1566-1572, 1997.

DUKE， S.H.; KAKEFUDA， G.; HENSON， C.A.; LOEFFLER, N.L.; VAN HULLE, N.M. Role of the testa epidermis in the leakage of intracellular substances from imbibing soybean seeds and its implications for seedling survival. Physiologia Plantarum, Copenhagen, v.68, n.4, p.625-631, 1986.

DUKE, S.H.; KAKEFUDA, G. Role of the testa in preventing cellular rupture during imbibition of legume seeds. Plant Physiology, Rockville, v.67, p.449-456, 1981.

HOEKSTRA, F.A.; GOLOVINA, E.A.; VAN AELST, A.C.; HEMMINGA, M.A. Imbibitional leakage from anhydrobiotes revisited. Plant, Cell and Environment, Oxford, v.22, p.1121-1131, 1999.

INTERNATIONAL SEED TESTING ASSOCIATION. Seed vigour testing. In: ISTA. International rules for seed testing. Bassersdorf: ISTA, 2004.

MARCOS FILHO, J. Germinação. In: Fisiologia de sementes de plantas cultivadas. Piracicaba: FEALQ, 2005. p.197-252.

MARCOS FILHO, J. Teste de envelhecimento acelerado. In: VIEIRA, R.D.; CARVALHO, N. M. (Ed.). Testes de vigor em sementes. Jaboticabal: FUNEP, 1999. p.133-149.

MIGUEL, M.V.C.; MARCOS FILHO, J. Potassium leakage and maize seed physiological potential. Scientia Agricola, Piracicaba, v.59, n.2, p.315-319, 2002.
PIETRZAK, L.N.; FRÉGEAU-REID, J.; CHATSON, B.; BLACKWELL, B. Observations on water distribution in soybean seed during hydration processes using nuclear magnetic resonance imaging. Canadian Journal of Plant Science, Ottawa, v.82, n.3, p.513-519, 2002.

RODRIGUES, M.B.C.; VILLELA, F.A.; TILLMANN, M.A.A.; CARVALHO, R. Pré-hidratação em sementes de soja e eficiência do teste de condutividade elétrica. Revista Brasileira de Sementes, Pelotas, v.28, n.2, p.168-181, 2006.

ROSA, S. D. V. F.; VON PINHO, E. V. R.; VIEIRA, M. G. G. C.; VEIGA, R. D. Eficácia do teste de condutividade elétrica para uso em estudos de danos de secagem em sementes de milho. Revista Brasileira de Sementes, Campinas, v. 22, n. 1, p.54-63, 2000.

ROSSETTO, C.A.V.; NOVEMBRE, A.D.L.C.; MARCOS FILHO, J.; SILVA, W.R.; NAKAGAWA, J. Comportamento de sementes de soja durante a fase inicial do processo de germinação. Scientia Agricola, Piracicaba, v.54, n.1/2, p.106-115, 1997.

SHEPHARD, H.; NAYLOR, R.E.L. Effect of the seeed coat on water uptake and electrolyte leakage of sorghum (Sorghum bicolor (L.) Moench) seeds. Annals of Applied Biology, Great Britain, v.129, p.125-136, 1996.

SMITH, A.M.; DENYER, K. Starch synthesis in developing pea embryos. New Phytologist, New York, v.122, n.1, p.21-33, 1992.

WANN, E.W. Leaching of metabolites during imbibition of sweet corn seed of different endosperm genotypes. Crop Science, Madison, v.26, p.731-733, 1986. 